Terakreditasi SINTA Peringkat 5

\title{
Rancangan Pengembangan Aplikasi Dokumentasi Clinical Pathway Berbasis Web
}

\author{
Adi Sadli \\ Program Sistem Ilmu Keperawatan \\ STIKES Tanawali Takalar \\ Sulawesi Selatan, INDONESIA \\ adisadli@gmail.com
}

\begin{abstract}
Clinical Pathway is a procedural model or service flow from a hospital to carry out clinical actions, usually starting from patient registration to patient discharge. The most important thing in implementing this Clinical Pathway is as a control function for the quality of hospital services. In practice, most of the procedural implementation is still done manually, meaning that it has not used a computerized system. Usually, Clinical Pathways are written in the form of a form with action instructions on one side, and service time on the other. The amount of service time is converted into days based on clinical instructions, but this can also differ depending on the development of the disease or existing actions, for example, Clinical Pathways for chronic diseases may have a number of weeks or months. The Clinical Pathway documentation application that will be designed is a web-based application that will be able to utilize the hospital's intranet/internet connection in its operation. This application is expected to be used as an answer to the need for faster, more effective, and measurable Clinical Pathways implementation. In its design, this application will continue to use the concept of procedural stages as done manually (according to Standard Operating Procedures) which has been carried out by the hospital, only the application is already in a computerized system where every aspect of the User will be connected to each other. For the design stage, this application itself is only intended for certain diseases such as Ischemic Stroke or depending on the needs of the Hospital. The implementation for this application is still being carried out on a trial basis, the aim is to obtain temporary data on how to see the impact of using this application on the level of service of the hospital that will be the executor of the trial of this application.
\end{abstract}

Keywords: Web Application; Clinical Pathway; Computerization; Standard Operating Procedure.

Abstrak - Clinical Pathway adalah suatu model prosedural atau alur pelayanan dari rumah sakit untuk melakukan tindakan klinis, biasanya mulai dari registrasi pasien sampai pemulangan pasien. Yang terpenting dalam pelaksanaan Clinical Pathway ini adalah sebagai fungsi kontrol untuk mutu pelayanan rumah sakit. Dalam prakteknya kebanyakan pelaksanaan prosedural ini masih dilakukan secara manual artinya belum menggunakan sistem yang ter-komputerisasi. Biasanya, Clinical Pathway ditulis dalam bentuk fomulir dengan instruksi tindakan di satu sisi, dan waktu pelayanan disisi yang lain. Banyaknya waktu pelayanan dikonversikan ke dalam hitungan hari berdasarkan instruksi klinik, namun hal ini juga dapat berbeda tergantung dari perkembangan penyakit atau tindakan yang ada, misalnya Clinical Pathway untuk penyakit kronis mungkin memilik jumlah waktu perminggu atau bulan. Aplikasi dokumentasi Clinical Pathway yang akan di rancang, merupakan aplikasi berbasis web yang nantinya bisa memanfaatkan koneksi intranet/internet rumah sakit dalam pengoperasionalnya, Aplikasi ini diharapkan bisa digunakan sebagai jawaban atas kebutuhan pelaksanaan prosedural Clinical Pathways yang lebih cepat, efektif dan terukur. Dalam perancangannya aplikasi ini akan tetap memakai konsep tahapan prosedural seperti yang dilakukan secara manual (sesuai Standar Operasional Prosedur) yang selama ini dijalankan rumah sakit hanya saja peng-aplikasiannya sudah dalam sistem yang ter-komputerisasi dimana setiap aspek pengguna akan saling terhubung satu sama lain. Untuk tahap perancangannya aplikasi ini sendiri hanya ditujukan untuk beberapa penyakit tertentu saja seperti misalnya Stroke Iskemik atau tergantung kebutuhan Rumah Sakit saja. Implementasi untuk aplikasi ini masih dilakukan secara ujicoba tujuannya untuk mendapatkan data sementara bagaimana melihat dampak penggunaan aplikasi ini dengan tingkat pelayanan rumah sakit yang akan menjadi pelaksana uji coba aplikasi ini.

Kata Kunci: Aplikasi Web; Clinical Pathway; Komputerisasi; Standar Operasional Prosedur.

1. Pendahuluan

Dalam undang-undang Praktik Kedokteran tahun 2004 tentang Undang-Undang Keperawatan ada pergantian istilah administratif dari sebelumnya dikenal istilah Standar Prosedur Operasional (SPO) diubah menjadi Panduan Praktik Klinis, tujuannya adalah untuk menyelaraskan pemahaman teknis yang kadang rancu, karena secara bahasa 'standar' bisa diartikan merupakan hal yang harus dilakukan pada semua keadaan, Maka secara teknis Standar Prosedur Operasional ini dibuat menjadi suatu Panduan Praktik Klinis atau bisa juga dikenal dengan istilah alur klinis (Clinical Pathway) [1]. 
Alur Klinis (Clinical Pathway) mempunyai beberapa nama, seperti collaborative care pathways, integrated care pathways, care pathway, multidisciplinary pathways of care, care map, pathways of care. Clinical Pathway disusun untuk memberikan detail kegiatan apa yang harus dilakukan pada kondisi klinis tertentu. Clinical Pathway juga menggunakan rencana tata laksana harian dengan standar pelayanan yang dianggap tepat. Clinical Pathway juga mempunyai pelayanan yang bersifat multidisiplin sehingga semua stakholder yang terlibat dalam pelayanan klinis termasuk dokter, apoteker, fisioterapis, nutrisionis/dietisien, perawat, dan lain-lain, Kelebihan sistem ini adalah monitoring kondisi pasien setiap hari, membuat intervensi dan memprediksi kondisi klinis pasien [2].

Clinical Pathway tertulis dalam format tertentu. Seperti terlihat pada Gambar 1 ada berbagai macam format Clinic Pathway tergantung jenis penyakit atau masalah yang menyertainya. Tapi secara umum format Clinical Pathway adalah tabel yang bagian kolom adalah variable waktu (hari atau jam), dan barisnya merupakan Tindakan atau observasi. Format dalam Clinical Pathway bisa menjadi lebih rumit dan terperinci (misalnya tindakan pemberian obut setiap 7 jam pada pasien dengan dosis tertentu). Format Tindakan Klinisnya bisa berupa check-list atau keterangan tindakan [3]. Adapun contoh formulir isian untuk tindakan klinis harian seperti pada Gambar 2.

\section{Metodologi}

Metode penelitian yang digunakan dalam perancangan aplikasi dokumentasi Clinical Pathway ini melalui beberapa tahapan yang dimulai dari identifikasi permasalahan, studi literatur, pengumpulan data, analisa kebutuhan system, coding dan desain aplikasi, running test dan evaluasi aplikasi. Dari data awal yang di peroleh ternyata rumah sakit memerlukan suatu sistem yang lebih baik, efisien, saling terhubung antara komponen yang satu dengan komponen yang lain dalam pelaksanaan langkah langkah klinis harian untuk melakukan tindakan terhadap pasien yang telah di diagnosa mempunyai penyakit tertentu, dan mempunyai dokumentasi pelaporan tindakan harian pada pasien yang lebih up to date dan bisa diakses secara mudah dan cepat, harapannya sistem ini bisa jadi rujukan untuk digunakan sebagai dasar evaluasi kebijakan dan pelayanan rumah sakit kedepannya [4].

Acuan yang di jadikan dasar dalam perancangan aplikasi ini sekaligus menjadi studi literasinya adalah setiap proses alur pemrograman atau flowchart dari aplikasi dokumentasi Clinical Pathway ini sebisa mungkin disesuaikan dengan "Pedoman Penyusunan Panduan Praktek Klinis dan Clinical Pathway Dalam Asuhan Terintegrasi Sesuai Standar Akreditasi Rumah Sakit 2012”, edisi I tahun 2015, serta memasukkan pula sumber literasi pendukung lainnya yang berasal dari konsultasi langsung dengan pihak rumah sakit, dari situs-situs kesehatan internet, dan dari sumber informasi alternatif lainnya yang dianggap perlu dan berhubungan dengan pembahasan yang ada dalam perancangan aplikasi Clinical Pathway ini [5].
Rancangan aplikasi yang akan dibangun menggunakan metode analisis perancangan perangkat lunak berbasis teknologi objek menggunakan permodelan Unified Modelling Language (UML) [6].

Uraian tahap-tahap dalam yang digunakan untuk menganalisis data yaitu (1) Identifikasi Aktor; pertama mengidentifikasikan orang atau perangkat yang akan digunakan dalam sistem. Orang atau perangkat ini disebut aktor. Dapat dikatakan aktor merupakan suatu yang berkomunikasi dengan sistem dan bagian eksternal dari sistem. Aktor mempresentasikan dari orang atau perangkat saat beroperasi. (2) Identifikasi Use Case; setelah aktor diidentifikasi, maka Use Case siap dikembangkan. Use Case mendeskripsikan interaksi antar aktor-aktor dengan sistem. (3) Pembuatan Diagram Use Case; Use Case dan aktor digunakan divisualisasikan, dispesifikasikan, dan didokumentasikan di diagram Use Case.

Untuk analisis kebutuhan system dalam perancangan aplikasi ini di putuskan untuk membuat aplikasi web based atau aplikasi berbasis web, tentu banyak pertimbangan ketika harus memutuskan untuk membuat dalam versi ini, terutama adalah masalah kecepatan akses dan kemudahnnya [7]. Selain karena akses aplikasi webbased yang bisa lebih cepat, ada pula keunggulan lainnya, di antaranya:

a) Tidak memerlukan instalasi

Karena salah satu sistem yang memakai system server-client maka aplikasi berbasis web tidak memerlukan instalasi seperti aplikasi berbasisi desktop yang biasa di lakukan pada komputer maupun gadget. Instalasi hanya dilakukan disisi server/hosting.

\section{b) Lebih update}

Ketika dalam perjalanannya aplikasi terdapat bugs dari aplikasi maka pihak programmer akan lebih mudah melakukan/perbaikan update aplikasi atau misalnya aplikasi bisa segera di update ker versi yang bisa menyesuaikan dengan perkembangan zaman. Maintenance dan update aplikasi hanya dapat dilakukan pada sisi server/hosting sehingga proses maintenance (pemeliharaan) berjalan lebih cepat.

\section{c) Multi-platform}

Aplikasi web juga bersifat multiplatform tidak hanya dijalankan oleh komputer tetapi juga dapat digunakan pada semua smartphonet. Hal ini tentu saja memudahkan pengguna untuk meng-akses aplikasi yang fleksibel dan cepat Kemudahan lainnya yaitu dapat mengakses aplikasi dimanapun dan kapanpun. Dan data yang di-input juga tersimpan secara otomatis di sistem server/ hosting/ cloud aplikasi.

\section{d) Sistem Operasi yang lebih fleksibel}

Seperti yang diketahui aplikasi desktop ataupun mobile bisa berjalan pada platform dan sistem operasi tertentu, sehingga aplikasi harus terus diperbarui sesuai kebutuhan. Dari beberapa kasus yang ada, aplikasi itu sudah tidak dapat digunakan, karena aplikasi yang ada di device pengguna sudah tidak up to date. Berbeda dengan aplikasi web-based yang berjalan pada browser karena 
aplikasi browser ini sudah ada secara default pada semua platform.

Apabila rancangan aplikasi dokumentasi Clinical Pathway ini telah jadi, maka rancangan ini akan diverifikasi terlebih oleh pihak manajemen Rumah Sakit. Dan jika sudah memenuhi standar yang dibutuhkan oleh rumah sakit maka perancangan aplikasi ini akan di tingkatkan menuju tahap pengembangan selanjutnya. Tapi jika dalam tahap evaluasi ini konsep yang diminta dianggap tidak sesuai yang di inginkan oleh pihak rumah sakit, maka perancangan ini akan di tinjau lagi.

\section{Hasil dan Pembahasan}

Aplikasi ini berbasis web jadi tidak memerlukan spesifikasi perangkat keras yang tinggi, untuk kebutuhan komputer atau laptop cukup dengan spesisifikasi minimum seperti Processor: CPU Min. 2.0 GHZ, Memory: Minimum 1 MB RAM, Harddisk: Kapasitas Min. 200 GB/DDR demikian juga untuk gadget/smartphone bisa berjalan pada spesifikasi yang minimum, atau lebih mudahnya bisa menggunalan server hosting/cloud.

Aplikasi dibuat dengan menggunakan bahasa pemrograman PHP 7.4 [8], database Mysql/MariaDB [9] dan framework codeigniter 3.10[10], browser seperti Chrome, Mozilla Firefox dan lain-lain.

Sistem ini dirancang untuk penggunaan multi User (on-line system), dengan memperhatikan kewenangan User, dalam pelaksanaannya aplikasi dokumentasi Clinical Pathway ini melibatkan komponen/User mulai dari administrator aplikasi, bagian registrasi/pendaftaran pasien, para dokter yang terdiri atas dokter IGD, spesialis, DPJP dan ruangan, perawat yang terdiri atas perawat primer dan perawat ruangan, ahli gizi, farmasi, laboratorium, radiologi, fisioterapi dan konsultasi. Semua komponen ini akan terhubung satu sama lain agar Clinical Pathway bisa terarah dan meng-efisiensikan waktu.

Alur proses bisnis aplikasi dokumentasi Clinical Pathway harian dapat dilihat pada Gambar 3 dibawah ini. Pada gambar terlihat bahwa tahapan pertama di mulai dengan melakukan registrasi pasien. Dimana dalam proses registrasi ini ada dua peng-inputan data yang harus dilakukan, yaitu me-registrasi pasien baru dan selanjutnya mengisi data diagnosa penyakit pasien. Untuk data pasien baru ada dua kondisi yang mesti diperhatikan ketika registrasi, apakah sistem ini akan terhubung dengan aplikasi rumah sakit misalnya Sistem Informasi Rumah Sakit, jika sudah terhubung maka operator tinggal menarik data pasien berdasarkan nomor rekam medik akan tetapi apabila belum terhubung maka dilakukan penginputan manual data pasien sesuai nomor rekam medik yang sudah ada.

Konsep jaringan berbasis LAN untuk aplikasi dokumentasi Clinical Pathway seperti pada Gambar 3. Alur proses bisnis aplikasi dokumentasi Clinical Pathway seperti Gambar 4. Dan Diagram Use Case Rancangan secara Umum seperti pada Gambar 5.

Tabel 1 merupakan hasil identifikasi aktor untuk sistem yang dirancang. Untuk identifikasi Use Case untuk sistem yang dirancang pada Tabel 2. Dan Tabel 3 adalah penjelasan dari Diagram Use Case Rancangan Pengembangan Aplikasi Dokumentasi Clinical Pathway Berbasis Web.

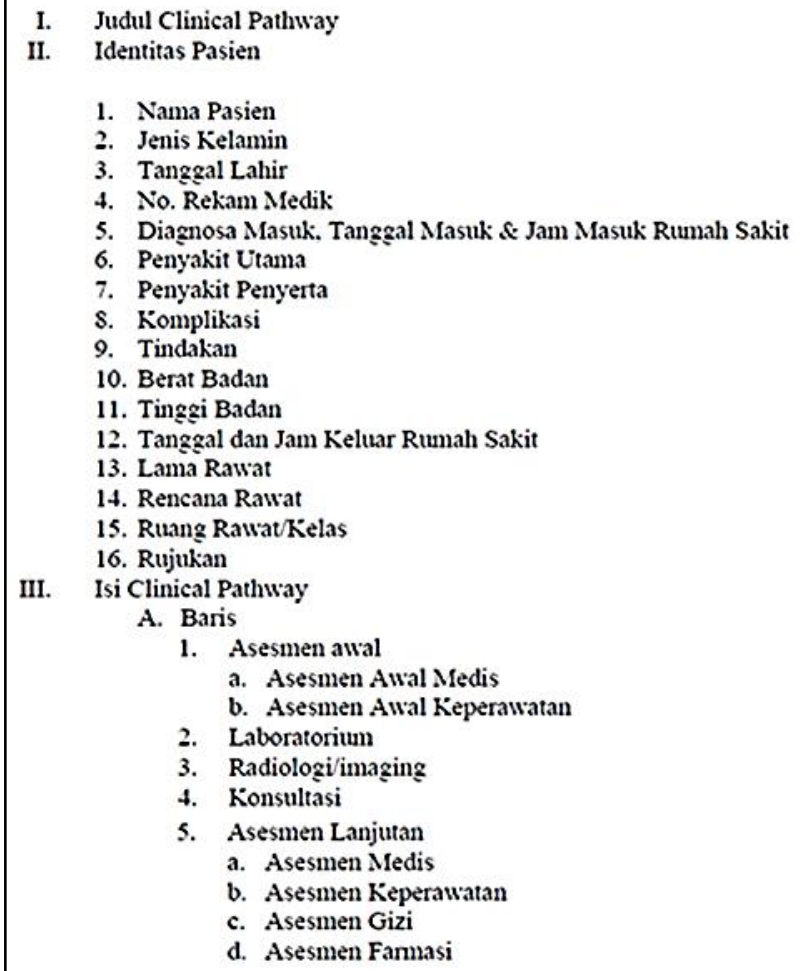

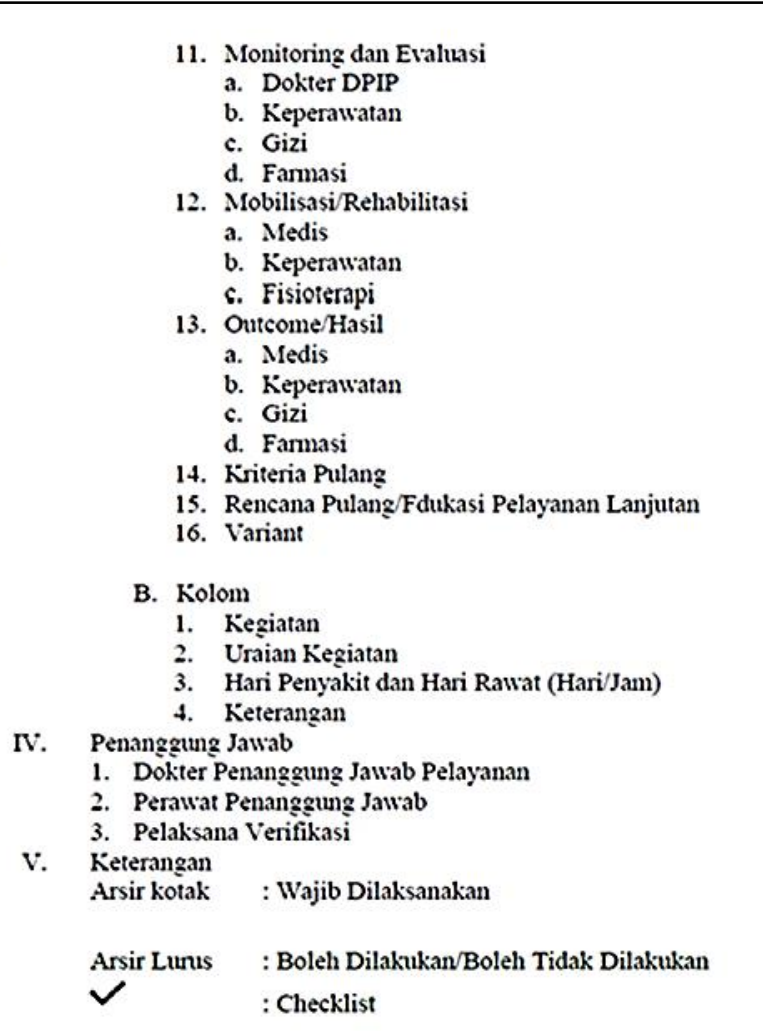

Gambar 1. Form Isian Clinical Pathway memuat tentang Identitas Pasien, Tindakan Klinis Terhadap Pasien 


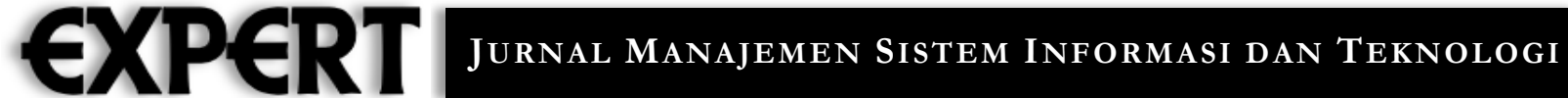

\begin{tabular}{|c|c|c|c|c|c|c|c|c|c|c|}
\hline \multirow{4}{*}{ No. } & \multirow{4}{*}{ Kegiatan } & \multirow{4}{*}{ Uraian Kegiatan } & \multicolumn{7}{|c|}{ Hari Penyakit } & \multirow{4}{*}{ Keterangan } \\
\hline & & & $1][2$ & $2 \sqrt{3}$ & 4 & 5 & 6 & 7 & 8 & \\
\hline & & & \multicolumn{7}{|c|}{\begin{tabular}{|l|} 
Hari Rawat \\
\end{tabular}} & \\
\hline & & & $1[2$ & 2 & 4 & 5 & 6 & 7 & 8 & \\
\hline \multirow[t]{8}{*}{1} & ASESMIEN AWAL & & & & & & & & & \\
\hline & ASESMEN AWAL MEDIS & & & & & & & & & \\
\hline & & Nyeri perut kanan bawah & & & & & & & & \\
\hline & & Nyeri tekan Mc Bumey & & & & & & & & \\
\hline & & Colok Dubur : Nyeri jam 9-11 & & & & & & & & \\
\hline & $\begin{array}{l}\text { ASESMEN AWAL } \\
\text { KEPERAWATAN }\end{array}$ & & & & & & & & & \\
\hline & & $\begin{array}{l}\text { Kondisi umum, tingkat kesadaran, } \\
\text { tanda - tanda vital, riwayat alergi, } \\
\text { skrining gizi, nyeri, status fungsional : } \\
\text { fisiko jatuh, risiko decubitus, } \\
\text { kebutuhn edukasi dan budaya }\end{array}$ & & & & & & & & \\
\hline & & $\begin{array}{l}\text { Kondisi umum } \\
\text { tingkat kesadaran } \\
\text { tanda-tanda vital } \\
\text { ziwayat alergi } \\
\text { screening gizi } \\
\text { ayeri } \\
\text { status fungsional : risiko jatuh, risiko } \\
\text { decubitus, kebutuhan edukasi dan } \\
\text { budaya } \\
\text { assesment biopsikososio dan spritual }\end{array}$ & & & & & & & & \\
\hline \multirow[t]{3}{*}{2} & LABORATORIUMI & & & & & & & & & \\
\hline & PEMERIKSAAN LAB & & & & & & & & & \\
\hline & & $\begin{array}{l}\text { HB, HT, WBC, TROMBOCYT, CT, } \\
\text { BT }\end{array}$ & & & & & & & & \\
\hline \multirow[t]{3}{*}{3} & RADIOLOGIIMLAGING & & & & & & & & & \\
\hline & $\begin{array}{l}\text { PEMERIKSAAN } \\
\text { RADIOLOGI }\end{array}$ & & & & & & & & & \\
\hline & & THORAX AP & & & & & & & & \\
\hline.. & $\ldots$ & & & & & & & & & \\
\hline 16 & $\begin{array}{l}\text { RENCANA } \\
\text { PULANG/EDUKASI }\end{array}$ & & & & & & & & & \\
\hline
\end{tabular}

Gambar 2. Contoh Formulir Isian Tindakan Klinis

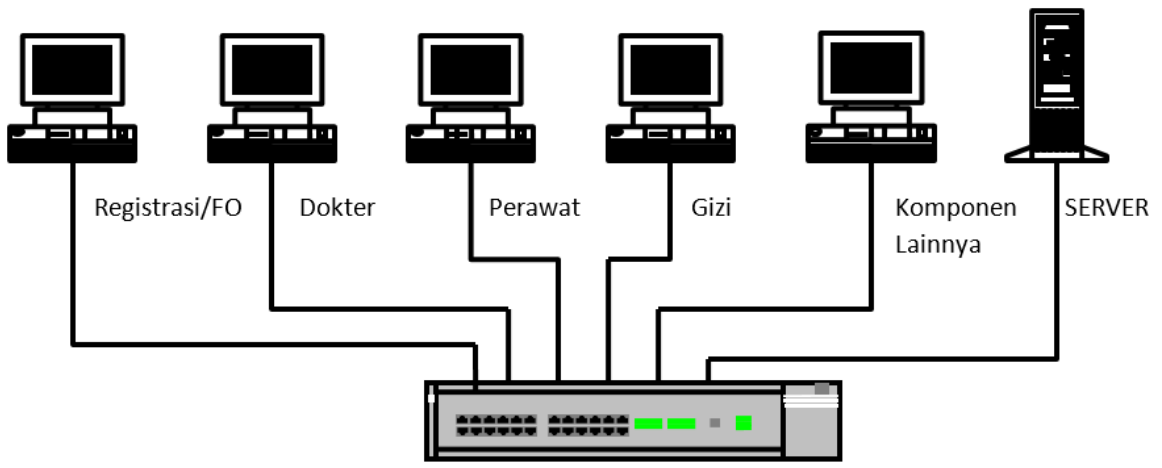

SWITCH

Gambar 3. Konsep jaringan berbasis LAN untuk aplikasi dokumentasi Clinical Pathway

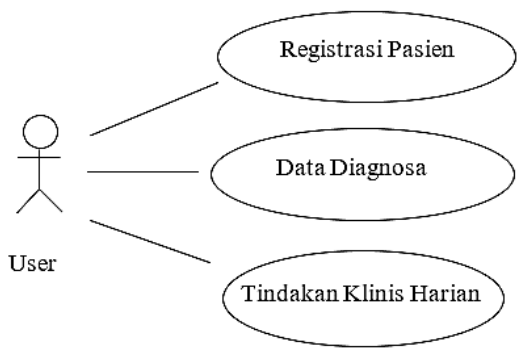

Gambar 5. Diagram Use Case Rancangan Secara Umum 


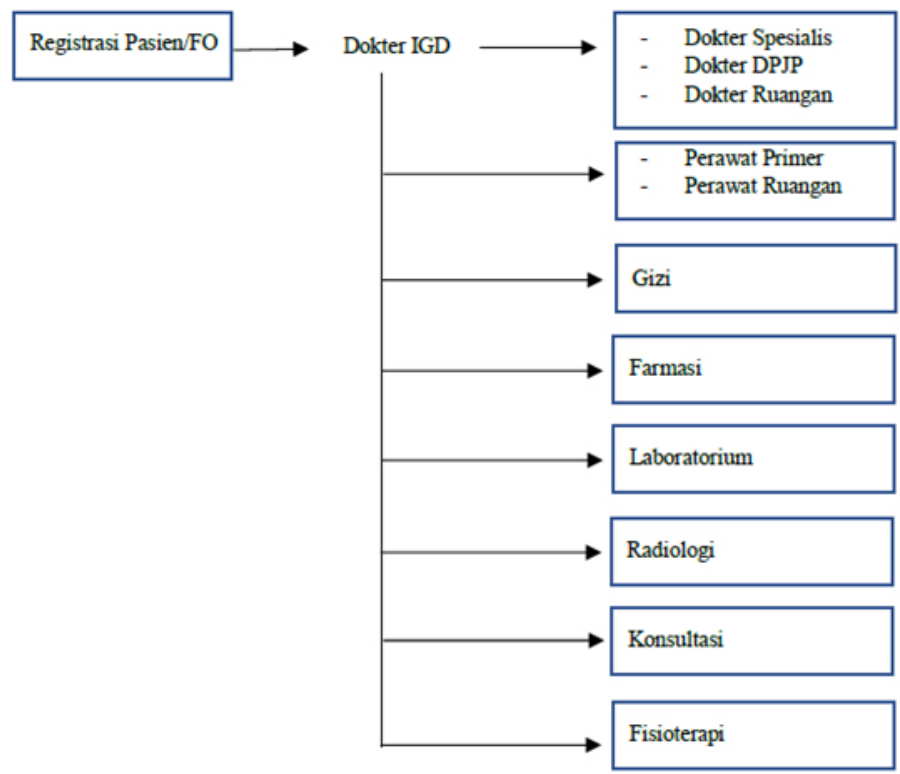

Gambar 4. Alur Proses Bisnis Aplikasi Dokumentasi Clinical Pathway

Tabel 1. Identifikasi Aktor Aplikasi Dokumentasi Clinical Pathway

\begin{tabular}{lll}
\hline Nama Aktor & Peran & Keterangan \\
\hline User (Pengguna) & $\begin{array}{l}\text { Sebagai User yang menggunakan } \\
\text { aplikasi dan menangani database. }\end{array}$ & User dapat menggunakan fasilitas aplikasi ini. \\
Database & $\begin{array}{l}\text { Sebagai media penyimpanan data } \\
\text { Database digunakan sebagai media penyimpanan data } \\
\text { dan digunakan juga pada fasilitas pencarian data. }\end{array}$ \\
\hline
\end{tabular}

Tabel 2. Identifikasi Use Case Aplikasi Dokumentasi Clinical Pathway

\begin{tabular}{|c|c|c|}
\hline Nama Use Case & Aktor yang berperan & Keterangan \\
\hline Main Menu & User(Pengguna) & Main Menu berisi fasilitas dalam aplikasi. \\
\hline Registrasi Pasien & User (Pengguna) & Registrasi Pasien dilakukan oleh bagian registrasi/Front Office \\
\hline $\begin{array}{l}\text { Input Data } \\
\text { Diagnosa }\end{array}$ & User (Pengguna) & Penginputan data diagnosa penyakit dilakukan juga oleh bagian \\
\hline $\begin{array}{l}\text { Check List } \\
\text { Tindakan Klinis } \\
\text { Harian }\end{array}$ & User (Pengguna) & $\begin{array}{l}\text { Meng-check list tindakan harian yang telah dilakukan sesuai } \\
\text { dengan pedoman isian Clinical Pathway berdasarkan kewenangan } \\
\text { masing-masing User. }\end{array}$ \\
\hline
\end{tabular}

Penjelasan dari Diagram Use Case Rancangan Pengembangan Aplikasi Dokumentasi Clinical Pathway Berbasis Web:

\section{a) Use Case Registrasi}

Aktor: User Registrasi. Tujuan: Input data pasien baru. Deskripsi: Dalam main menu disediakan fasilitas untuk menginput data baru pasien, apabila sudah punya akses ke sistem informasi rumah sakit bisa langsung tarik data tapi apabila belum input data pasien langsung dengan rerfernsi nomor rekam medik yang ada.

\section{b) Use Case Data Diagnosa}

Aktor: User Registrasi. Tujuan: Mengisi data diagnosa penyakit pasien. Deskripsi: Menginput data diagnose penyakit pasien, tanggal masuk, penyakit utama, penyerta, komplikasi, berat, tinggi dan lain-lain. Setalah proses ini selesai maka akan langsung mengirimkan notifikasi (pemberitahuan) ke User Dokter IGD.

\section{c) Use Case Tindakan Harian}

Aktor: User Dokter IGD. Tujuan: Melakukan check list tindakan klinis harian pasien. Deskripsi: Memastikan apakah tindakan klinis harian boleh dilakukan atau tidak dengan memperhatikan keterangan tindakan. Setelah data di simpan maka akan mengirimkan notifikasi ke User selanjutnya.

\section{d) Use Case Tindakan Harian}

Aktor: User Dokter Spesialis, Dokter DPJP, Dokter Ruangan, User Perawat Primer, Perawat Ruangan, Gizi, Farmasi, Laboratorium, Radiologi, Konsultasi dan Fisioterapi. Tujuan: Melakukan check list tindakan klinis harian pasien. Deskripsi: Melakukan check list tindakan klinis harian pasien apakah sudah dilakukan tindakan atau belum, sesuai kewenangan masing masing User.

Proses bisnis diatas akan berlangsung harian sesuai jumlah hari yang di tentukan dalam form Clinical Pathway dan tindakan klinis untuk User yang berwenang. 
Karena aplikasi berbasis web, maka aplikasi ini bisa di akses menggunakan browser yang ada di desktop dan mobile phone. Gambar 6 dan Gambar 7 memperlihatkan tampilan awal/dashboard aplikasi di komputer maupun smart phone.

Tampilan dashboard aplikasi ketika pertama kali User login, di sebelah kiri ada menu aplikasi dan bagian tengah/konten berisi grafik jumlah pasien yang di layani dan bagian top bar ada menu notifikasi dan profil User.

Untuk menjalankan aplikasi ini sesuai Alur Klinisnya, maka pertama kali pasien harus di registrasi dulu. Dimana tujuannya adalah menyimpan data pasien dalam master data atau bank data pasien. Seperti terlihat pada Gambar 8. Dan yang melakukan registrasi ada bagian operator atau orang yang di tunjuk. Operator ini juga harus login terlebih dahulu untuk menggunakan aplikasi ini.

Setelah operator menginput data pasien, kemudian operator atau bagian registrasi adakan menginput data pasien tadi ke dalam data diagnosa pasien, Operator tinggal memasukkan apa diagnosa penyakit pasien dan mengisi form yang ada, seperti Gambar 9.

Data diagnosa yang diinput akan langsung terkirim ke dokter IGD dalam bentuk notifikasi, dan ketika dokter IGD login di aplikasi maka akan mendapat pemberitahuan mengenai pasien yang akan di beri tindakan klinis. Form notifikasinya terlihat seperti Gambar 10.
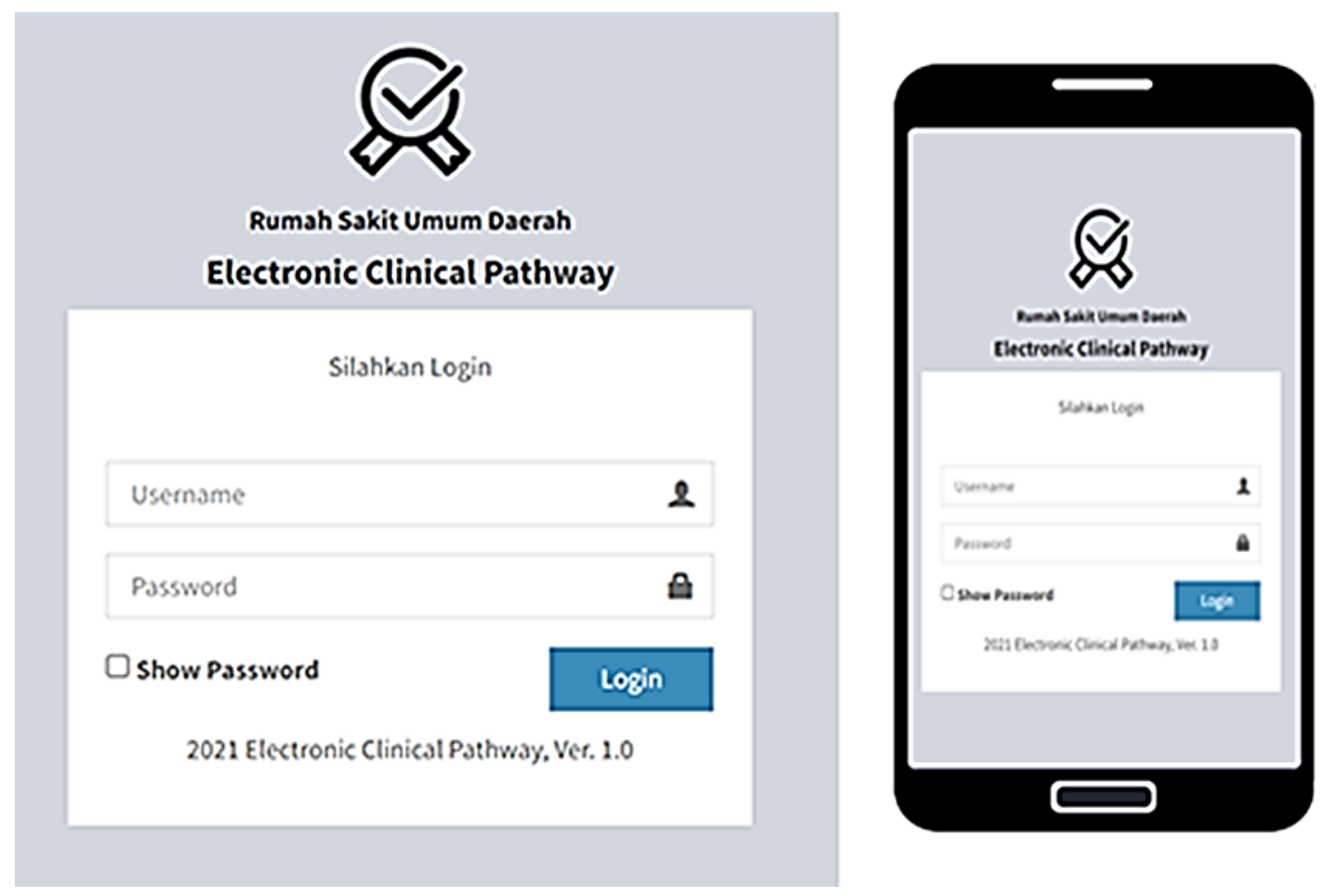

Gambar 6. Interface aplikasi dokumentasi Clinical Pathway di browser dan smartphone (login page)

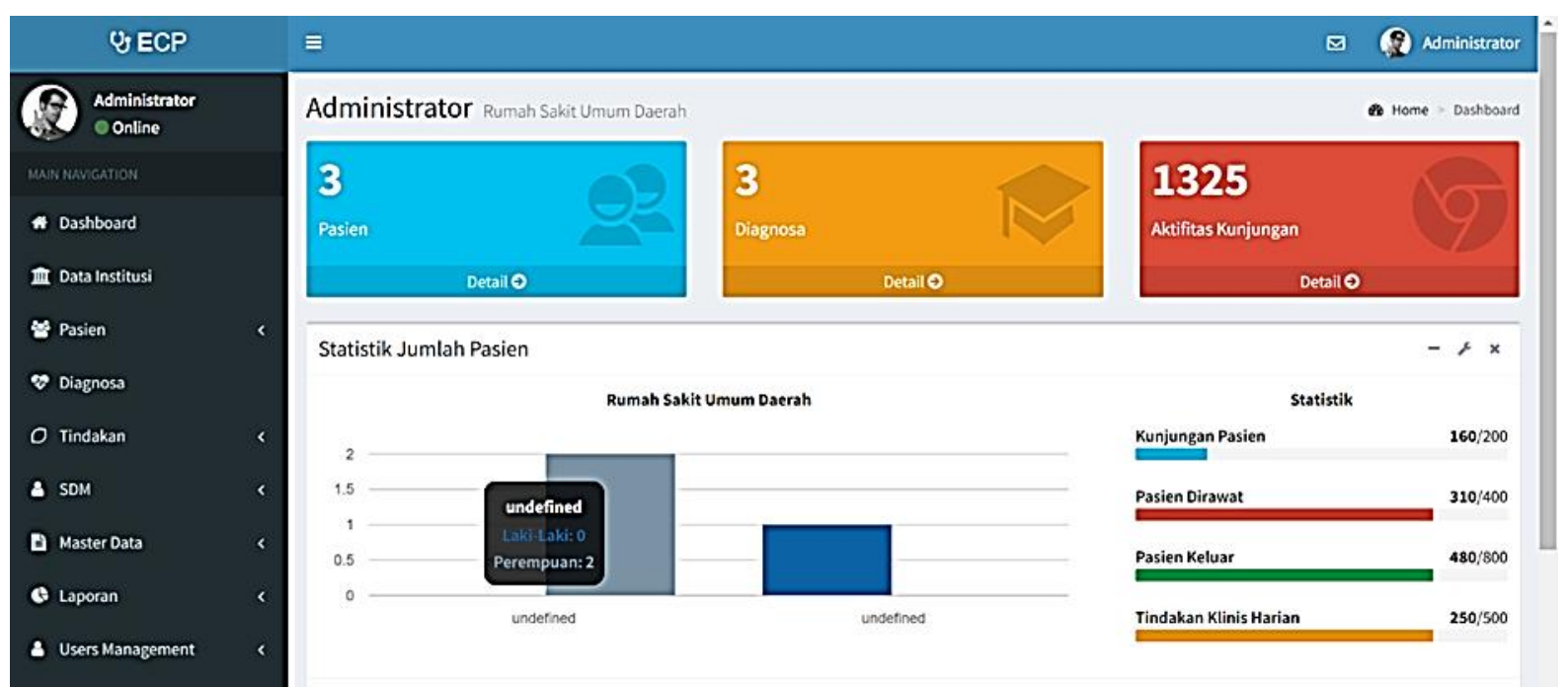

Gambar 7. Tampilan Menu dan Dashboard User 


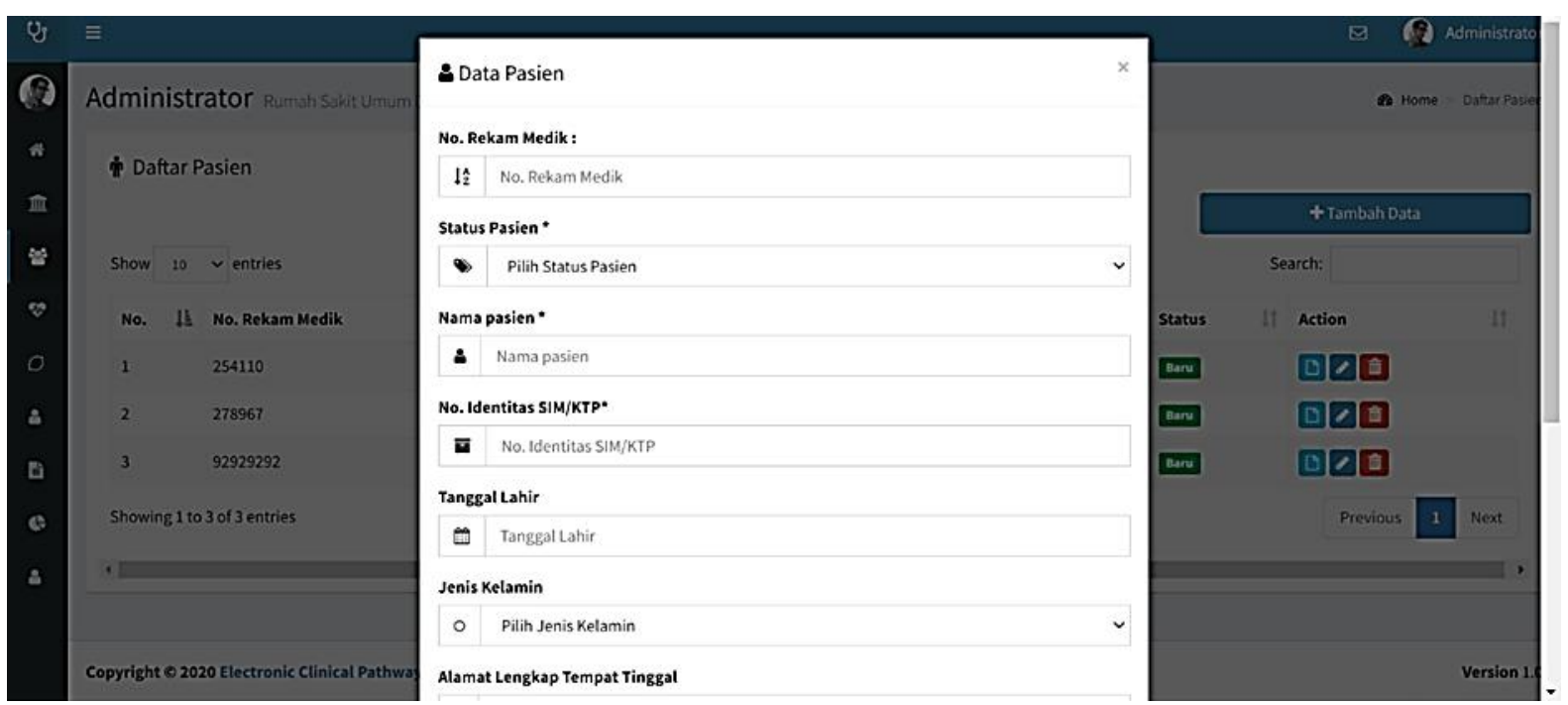

Gambar 8. Form Inputan Pasien, dimana operator bagian registrasi akan menginput data pasien

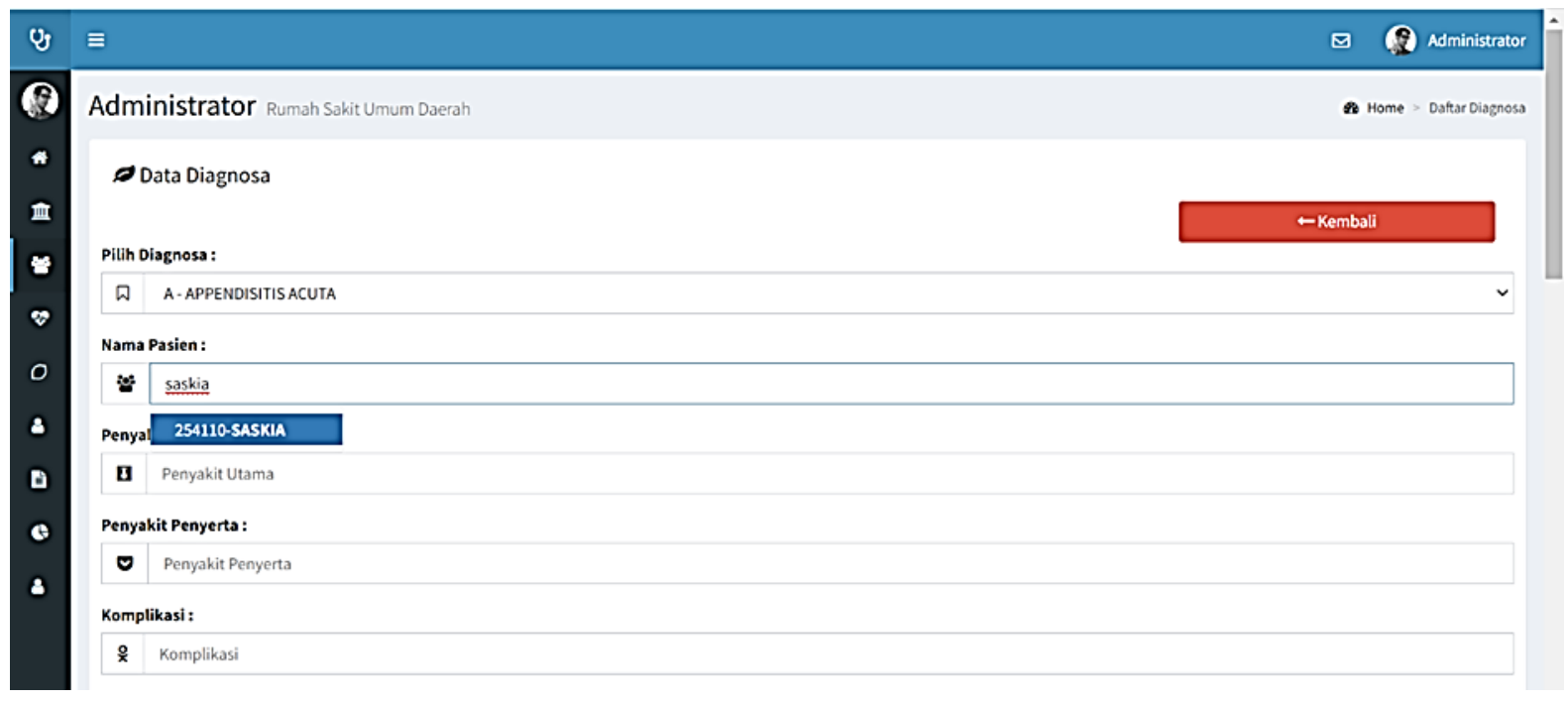

Gambar 9. Form Inputan Data Diagnosa Pasien

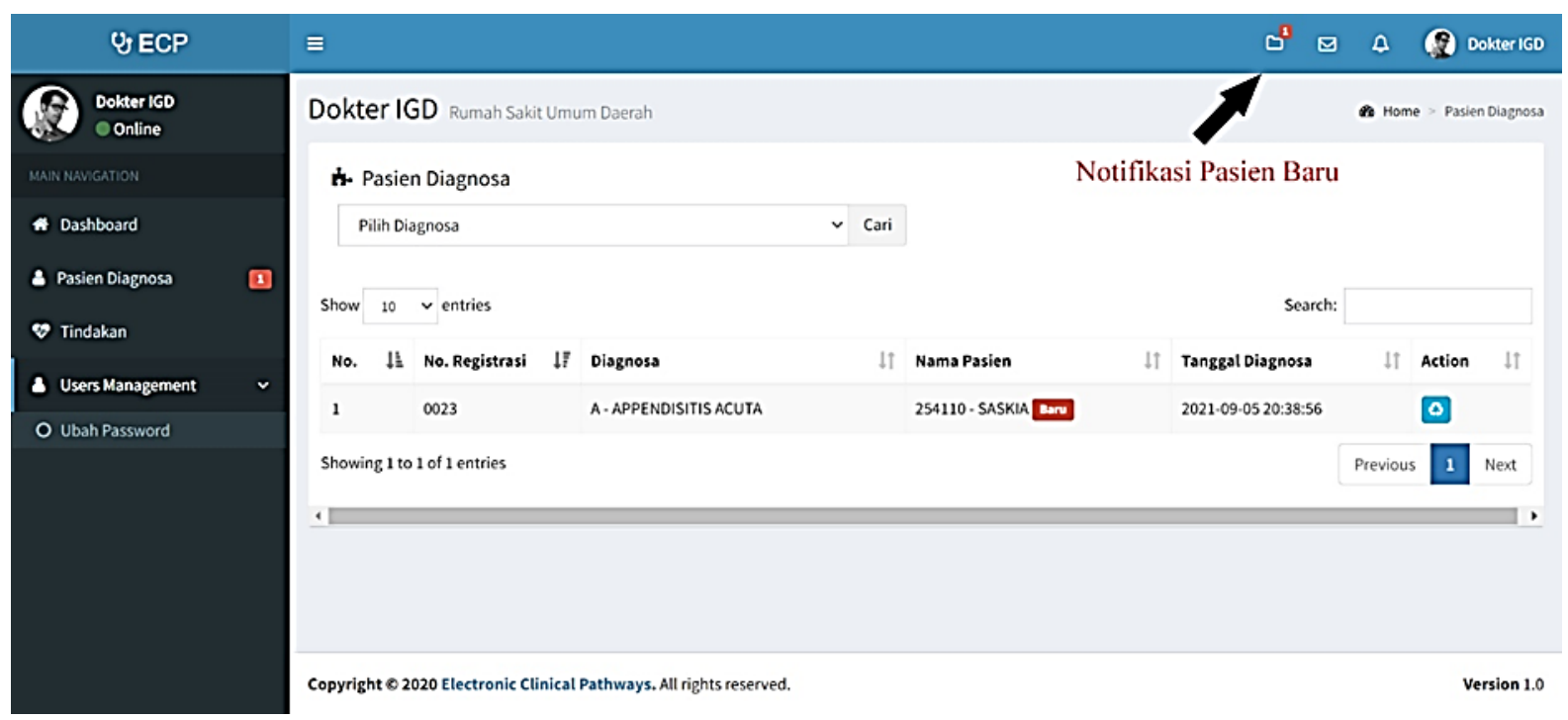

Gambar 10. Notifikasi ke dokter IGD untuk melakukan check list tindakan klinis 
Kemudian dokter IGD akan melakukan tindakan klinis pada pasien dan mengisi form tindakan klinis yang telah di lakukannya berupa cek list seperti terlihat pada Gambar 11, setelah selesai maka dokter IGD akan menyimpan data ini, yang akan kemudian di teruskan ke semua stakholder yang terlibat dalam pelayanan klinis termasuk dokter, apoteker, fisioterapis, nutrisionis/ dietisien, perawat, dan lain-lain dimana semua stakeholder ini harus login juga untuk bisa mengakses aplikasi ini.
Setelah semua alur klinis dilakukan oleh stakeholder yang terlibat maka akan muncul pelaporan apa-apa tindakan klinis yang teklah di lakukan kepada pasien yang terlihat pada Gambar 12.

Peringkat toko terbaik dihitung dengan mengalikan setiap bobot kriteria yang telah dihitung dengan metode AHP dengan masing-masing nilai yang dinormalisasi dan dijumlahkan semuanya dan mendapatkan nilai pilihan (preference) atau skor akhir. Angka apa pun yang lebih besar atau lebih besar akan menentukan toko yang direkomendasikan terbaik

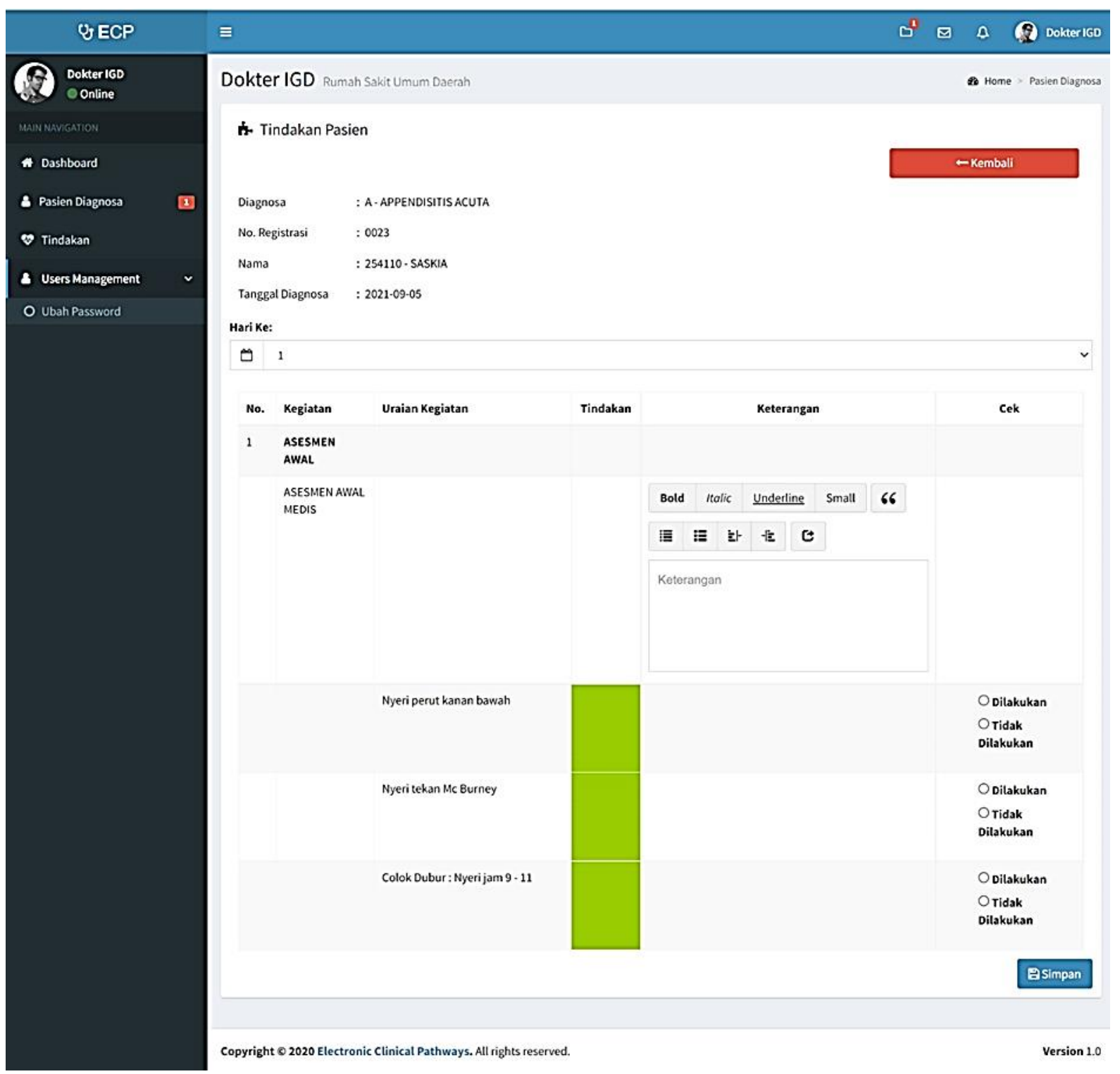

Gambar 11. Form check list tindakan klinis harian 


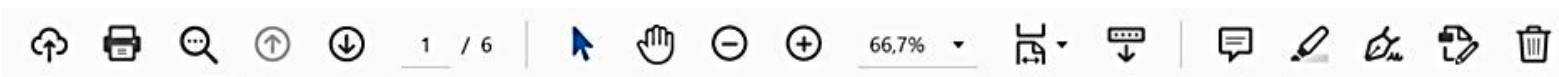

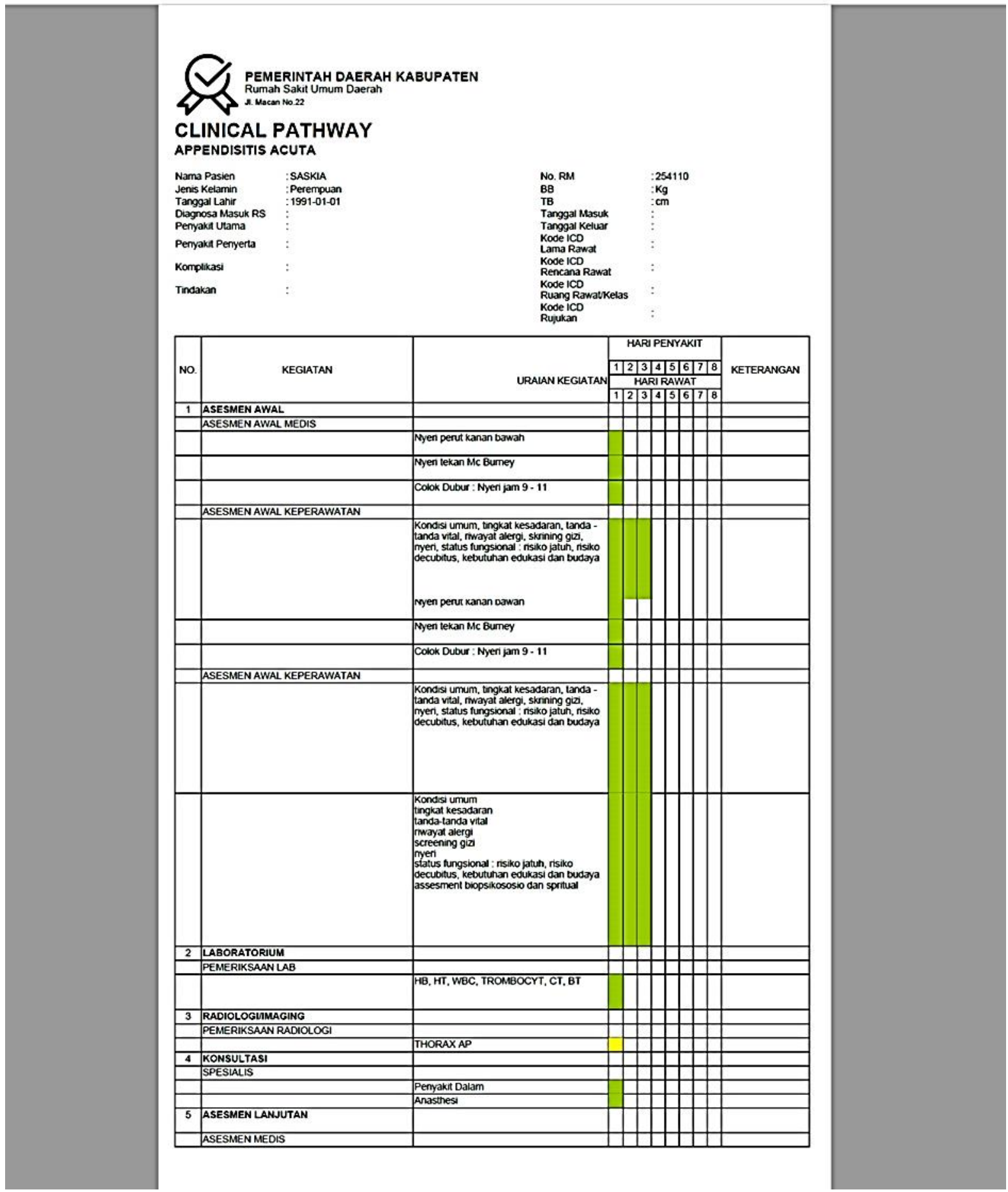

Gambar 12. Print out check-list tindakan klinis harian

\section{Kesimpulan}

Rancangan aplikasi ini masih tahap ujicoba tentunya agar mendapatkan hasil yang akurat, maka harus dilakukan pengujian dan menggunakan lebih banyak data uji/training data. Untuk sistematika alur program sangat mudah dipahami karena terstruktur. Aplikasi ini adalah model pengarsipan digital yang menyimpan data harian aktifitas klinis pasien, meliputi tindakan, penggunaan obat-obatan, takaran asupan gizi dan lain sebagianya, data ini nanti bisa memudahkan tenaga medis(dokter, perawat, dan lain-lain) untuk pengambilan keputusan dan memberikan semacam rekomendasi terkait tindakan tindakan klinis tertentu dimasa depan.

Berdasarkan hasil dari analisis, saran untuk pengembangan lebih lanjut yaitu setelah aplikasi ini nantinya benar-benar dijalankan dan telah disesuaikan dengan pola layanan rumah sakit mungkin bisa di 
kembangkan ke dalam platform aplikasi lain seperti di Android atau iOS. Aplikasi harus digunakan untuk mengetahui dimana bugs/error dan kekurangan aplikasi ini sehingga dapat dijadikan referensi untuk penyempurnaan aplikasi dokumentasi Clinical Pathway kedepannya.

\section{Daftar Pustaka}

[1] M. Siswanto, D. Chalidyanto, "The Effect of Clinical Pathway Compliance on Reducing Length of Stay - Pengarub Kepatuban Alur Klinis Dalam Menurunkan Lama Rawat Inap", Siloam Surabaya Hospital, Indonesia, 1 Juni 2020 .

[2] RS Umum Metro Medical Center, "Panduan Clinical Pathway RS Umum Metro Medical Center", Lhokseumawe, 2018.

[3] G. Endradita, "Panduan Pembuatan Clinical Pathway", Diakses 15 Agustus 2021, Tersedia: https://galihendradita.wordpress.com/2017/04/2/ panduan-pembuatan-clinical-pathway/

[4] I. Gusti, "Dampak Penerapan Clinical Pathways pada Pasien DBD Terhadap Outcome Pelayanan di RSUD Taman Husada Bontang", Program Pascasarjana Universitas Hasanuddin Makassar, 2017.
[5] Perdatin Aceh, "Pedoman Penyusunan Panduan Praktek Klinis dan Clinical Pathway Dalam Asuban Terintegrasi Sesuai Standar Akreditasi Rumah Sakit 2012", Edisi I, 2015, Diakses 15 Agustus 2021, Tersedia: https://perdatinaceh.files.wordpress.com.

[6] Dicoding Intern, "Apa itu UML? Beserta Pengertian dan Contohnya", 12 Mei 2021, Diakses 15 Agustus 2021. Tersedia: https://www.dicoding.com/blog/apa-ituuml/

[7] Folarium, "Perbedaan Aplikeasi Web Base dan Dekstop", Diakses 22 Agustus 2021, Tersedia: https://www.folarium.co.id/articles/perbedaanaplikasi-web-base-dan-dekstop/

[8] Duniailkom, "Tutorial Belajar PHP Part 1: Pengertian dan Fungsi PHP dalam Pemrograman Web", Diakses 22 Agustus 2021, Tersedia: https://www.duniailkom.com/pengertian-danfungsi-php-dalam-pemograman-web/

[9] E. O. Choiri, "Mengenal MariaDB, Fungsi dan Bedanya dengan MySQL", Diakses 23 Agustus 2021, Tersedia: https://qwords.com/blog/mariadb-adalah/

[10] Y. Purbadian, "Framework Codeigniter", CV. Asfa Solution Software Development, IT dan Publishing, 2016. 